\section{$\checkmark$ Research Square}

Preprints are preliminary reports that have not undergone peer review.

They should not be considered conclusive, used to inform clinical practice, or referenced by the media as validated information.

\title{
Increasing aridity may reduce productivity and soil organic carbon storage with woody plant encroachment
}

\section{Yunhua Liu}

Xinjiang Agricultural University

Junhui Cheng

Xinjiang Agricultural University

Bernhard Schmid

Xinjiang Agricultural University

Jiandong Sheng ( $\nabla$ sjd@xjau.edu.cn )

Xinjiang Agricultural University https://orcid.org/0000-0003-3062-1126

\section{Research Article}

Keywords: Woody plant encroachment, Pure grasslands, Wooded grasslands, Soil organic carbon, Grassland types, Aboveground primary productivity

Posted Date: September 30th, 2021

DOI: https://doi.org/10.21203/rs.3.rs-947316/v1

License: (9) This work is licensed under a Creative Commons Attribution 4.0 International License. Read Full License 


\section{Abstract}

\section{Aims}

We have found a positive effect of woody plants on total plant carbon (C) storage in less arid grassland was shifted to a negative effect in arid grasslands in Xinjiang, a typical arid region in China. In this study, we further assessed the effects of woody plants on aboveground primary productivity (ANPP) and soil organic $C(\mathrm{SOC})$ storage and explored the mediation of climate conditions on these effects. We also aimed to elucidate the reasons for the effects on SOC storage in terms of ANPP and belowground biomass $\mathrm{C}(\mathrm{BGC})$.

\section{Methods}

We compared the difference in ANPP and SOC content between pure and wooded grasslands and evaluated the relation between SOC content and ANPP and BGC in six grassland types along the altitude (climatic) gradients.

\section{Results}

In three arid types, woody plants had a negative effect on ANPP due to their more negative impacts on herbaceous plants and lower ANPP. The negative effect on ANPP and BGC led to that on SOC storage in these types. In less arid types, there had a positive effect on ANPP because woody plants had weaker negative impacts on herbaceous plants and higher ANPP. A positive effect on ANPP combined with a neutral impact on BGC contributed to a positive effect on SOC storage in these types.

\section{Conclusions}

Woody plants had a negative effect on ANPP and SOC storage in most arid grasslands in Xinjiang. We predicted that increasing aridity may reduce ANPP and SOC storage with woody plant encroachment in the future.

\section{Introduction}

Woody plant encroachment into grassland, characterized with the increases in the density, cover and biomass of native or exogenous woody plants, has been frequently reported worldwide, especially in arid and semiarid regions during the past century (Asner et al. 2003; Hughes et al. 2006; Van Auken 2000). The possible reasons for this phenomenon are grazing regime changes, nitrogen deposition, $\mathrm{CO}_{2}$ concentration increasing and their complex interactions (D'odorico et al. 2012; Eldridge et al. 2011; Hibbard et al. 2003; Hughes et al. 2006; Van Auken 2000). Woody plant encroachment has a potential to alter the functions and processes of grasslands (Eldridge et al. 2011). How it alters the amount of carbon 
(C) sequestered in soil, an important function of grasslands, has attracted many interests from ecologists because grasslands contain approximately $10 \% \sim 30 \%$ of global soil organic C (SOC) and any tiny change in the amount of SOC in grasslands will have an important implication to the global $\mathrm{CO}_{2}$ concentration and related climate change (Jackson et al. 2002; Scurlock and Hall 1998; Tang et al. 2018).

Woody plant encroachment is likely to alter SOC storage because woody plants differ from herbaceous plants in terms of productivity, biomass allocation pattern and the quantity and quality of litter (Hibbard et al. 2003; Jackson et al. 2002; Wessman et al. 2012). In addition, the changes in physiognomic types from pure to wooded grasslands may also affect soil temperature, moisture and microbial biomass and activity, thereby affecting SOC decomposition and accumulation (Mcculley et al. 2004). However, the magnitude and direction of change in SOC storage with woody plant encroachment are highly mixed (Eldridge et al. 2011). Moreover, few studies have gave a lucid explanation for the change in SOC storage. Several studies reported that SOC content increased, which may result from the increasing in the amount and lignification of litter inputs or the slower turnover of soil organic matter associated with the improvement in microclimate in wooded grasslands (Montané et al. 2010; Smith and Johnson 2004). However, Jackson et al. (2002) found SOC content decreased in wetter sites in south-western United State. Hughes et al. (2006) and Smith and John (2003) reported no net change in SOC storage. These effects are inconsistent may be due to the mediation of abiotic and biotic factors. For example, SOC are more likely to accumulates in fine-textured than in coarse- textured soil after woody plant encroachment (Liao et al. 2006). Grazing can dampen the positive effects on plant diversity and multifunctionality in arid region (Eldridge et al. 2013).

Meta analyses or regional studies found climate conditions could also mediate the change in SOC storage with woody plant encroachment. However, the mediation of climate conditions is complex, which may be at least due to the different spatial scale of analysis. For example, Jackson et al. (2002) found that, in the south-western United States, SOC content increased at drier sites and decreased at wetter sites and there was a negative relationship between the change in SOC storage and mean annual precipitation (MAP). In contrast, Li et al. (2016) reported that at a global scale, the change in SOC was positively correlated with MAP and mean annual temperature (MAT). Previous studies posited that the mechanisms for the mediation of climate conditions was through their influences on the quantity of plant inputs and the rates of decomposition outputs (Wheeler et al. 2007). However, few studies have assessed the change in SOC storage with woody plant encroachment and that in plant inputs to it, such as primary aboveground productivity (ANPP) simultaneously and this mechanism needs a further confirmation.

Most of previous works studied the effect of woody plant encroachment through comparing paired wooded grasslands and adjacent or former pure grasslands at a plot scale in a given site with similar environmental conditions (e.g. Knapp et al. 2008). Xinjiang, located in Northwest China, is a typical arid and semi-arid region. Woody plants are a common vegetative component in Xinjiang grasslands. In Xinjiang, the special landforms that three mountains and two basins are arranged alternatively makes precipitation and temperature change regularly with altitudes increasing. In the classification system of China's grasslands, grassland types can well reflect this variation in climate conditions along the altitudes 
$(\mathrm{Xu}, 1993)$. It is not clear to us that whether Xinjiang grasslands experienced woody proliferation. However, we can predict the future changes in $\mathrm{C}$ storage following woody plant encroachment through assessing the effects of existing woody plants on $\mathrm{C}$ storage along the altitude (climatic) gradients. Our previous work has selected six grassland types along the altitudinal (climatic) gradients across Xinjiang, and used a large number of replicate but unpaired pure and wooded grassland sites (a total of 284 sites) and a consistent sampling and measuring methods to examine the effects of woody plants on plant $C$ storage and the mediation of climate conditions on these effects. We found a positive effect of woody plant encroachment on plant $\mathrm{C}$ storage in less arid grassland types at higher altitudes was shifted to a negative effect in arid types at lower altitudes. In this study, we still used the same sites as our previous work and aimed to further assess the effects of woody plant encroachment on SOC storage and ANPP, another indicator of functions and processes of grasslands. We predicted that climatic conditions also mediated the effects on ANPP and SOC storage and the effects varied with grassland types. Our previous work found that woody plants increased the living aboveground $C$ (AGC) across the six grassland types but the magnitude of increase was weaker in three arid types. We predicted the effects on ANPP was analogous to that on the living AGC. Despite the increases in ANPP, we predicted a negative effect on SOC storage in three arid types because our previous work found a negative impact of woody plants on vegetation-level belowground biomass C (BGC), a more important plant inputs to SOC (Pregitzer 2002). We predicted a positive effect on SOC storage in less arid types due to a more positive effect on ANPP and a neutral impact of woody plants on BGC in these types that we have found in previous study. In this study, we also aimed to elucidate the reasons for the effects of woody plants on SOC storage and to confirm the mediation of climate conditions on these effects in terms of ANPP and BGC.

\section{Materials And Methods}

Study area

Xinjiang is the biggest province in China, far away from the sea and situated the inland. There are high mountains around it and the ocean air flow is not easy to reach, forming a typical temperate continental climate characterizing with low rainfall, high evapotranspiration, long sunshine time, cold winter and hot summer. There are three mountain ranges in the north, south and middle of Xinjiang, respectively and two basins lie between them. Natural grasslands are widely distributed in these mountains and basins. The area of natural grasslands is $5.72 \times 10^{7}$ ha, accounting for 34.4 percent of the total land area of Xinjiang (Xu 1993).

Sampling sites

We first selected six grassland types with precipitation as water source and woody plant presences. Along the altitudes, these selected types are temperate desert, temperate steppe desert, temperate desert steppe, temperate steppe, temperate meadow steppe (hereafter the word "temperate" were omitted in these type names) and mountain meadow. 
Then we used the distribution map of Xinjiang grasslands (1:1 000000$)$ and selected grassland forms (grassland forms is the most basic classification unit in the classification system of China's grasslands and named by dominant species) dominated only by herbaceous plants and only by woody plants. The distribution map of Xinjiang grasslands was drew in the 1980s, so woody plants were present at least 30 years ago. Here, herbaceous plants indicate any grasses or herbaceous species while woody plants include shrubs and trees (House et al. 2003). Among these forms, we further selected ones which are common and have a large distribution area. In each grassland form, there had at least three sampling sites. There is little international agreement on the name and classification of mixed woody-herbaceous systems (House et al. 2003). In our study, wooded grasslands were defined as grasslands where the relative aboveground biomass of woody plants are greater than or equal to $50 \%$. Pure grasslands defined as grasslands where woody plants are not present. After surveying and measuring, we excluded the sampling sites with heavy grazing and where woody plants were present but their relative biomass were lower than 50\%. Finally, there were 284 sampling sites covering 87 grassland forms. See Table 1 and Fig. 1 in our previous work and Table 1 in this study for more description of the location and sampling sites (Liu et al. 2020).

Table 1

Aridity index of the six grassland types

\begin{tabular}{|llllll|}
\hline TD & TSD & TDS & TS & TMS & MM \\
\hline $1.32 \pm 1.33$ & $7.92 \pm 1.48$ & $4.89 \pm 1.40$ & $3.18 \pm 0.62$ & $2.42 \pm 0.53$ & $2.02 \pm 0.44$ \\
\hline $\begin{array}{l}\text { TD: temperate desert; TSD: temperate steppe desert; TDS: temperate } \\
\text { steppe; TMS: temperate }\end{array}$ meadow steppe; & TS: & TS: temperate \\
\hline
\end{tabular}

Plant sampling and analysis

In this study, ANPP was expressed as the $\mathrm{C}$ quantity per square metre and obtained by multiplying the peak biomass produced in the current year by their $\mathrm{C}$ content. The peak biomass sampling was conducted in mid-July to early August from 2011 to 2013. In each sampling site, a 100m $\times 100 \mathrm{~m}$ sampling plot was set. On each side of one diagonal of plot, five $1 \mathrm{~m} \times 1 \mathrm{~m}$ quadrats at $20-\mathrm{m}$ intervals were established and they were staggered. In each sampling site of wooded grasslands, there had two and three additional $5 \mathrm{~m} \times 5 \mathrm{~m}$ quadrats at 20 -m intervals on two sides of this diagonal. The five $1 \mathrm{~m} \times 1 \mathrm{~m}$ quadrats of ten $1 \mathrm{~m} \times 1 \mathrm{~m}$ ones were uniformly arranged at the same position in five $5 \mathrm{~m} \times 5 \mathrm{~m}$ quadrats, such as the lower right corner.

In $1 \mathrm{~m} \times 1 \mathrm{~m}$ quadrats, all the green parts of herbaceous plants was collected by clipping to ground level. The current year biomass of woody plants were harvested by species. For woody species with a high number of plants, all the plants were classified into three size levels based on the crown diameter, i.e., large $(>1 \mathrm{~m})$, intermediate $(0.5 \sim 1 \mathrm{~m})$ and small $(<0.5 \mathrm{~m})$. The quantity of individuals in each size class were recorded and then randomly selected 3,5 and 10 plants in the large, intermediate and small size classes, respectively. For woody plant individuals with intermediate and large sizes, we sampled onequarter or one-eighth of the whole plant. For woody species that were low in number, we sampled all the 
plants of this species. The sampled parts were separated into leaves, current-year twigs, stem, flower and fruit.

In the lab, all the plant material was dried at $60^{\circ} \mathrm{C}$ for $48 \mathrm{~h}$ and weighed, then ground in a ball mill (Retsch MM20, Germany). Then the $C$ concentration was measured using an elemental analyser (Euro Vector EA3000, Italy). The ANPP of herbaceous plants was determined by multiplying the living biomass of herbaceous plants by their $\mathrm{C}$ concentration. For each sampled woody plant, the ANPP was the sum of the product of leaves, current-year twigs, flower and fruit and their respective $C$ concentration. ANPP of a given species in a $5 \mathrm{~m} \times 5 \mathrm{~m}$ quadrat was calculated by multiplying the average ANPP for each size class with the corresponding number of woody plant individuals. The ANPP in a $5 \mathrm{~m} \times 5 \mathrm{~m}$ quadrat was the sum of ANPP all the woody species.

BGC were expressed as the amount of C per square meter. See our previous work (Liu et al. 2020) for its sampling and analysis.

Soil sampling and analysis

After plant sampling, soil profiles were dug in two and three $1 \mathrm{~m} \times 1 \mathrm{~m}$ quadrats at $20-\mathrm{m}$ intervals on both sides of the diagonal of sampling plot, respectively. This soil sampling method can address the spatial heterogeneity of SOC storage caused by woody plants. Soil samples for $\mathrm{C}$ content analysis were taken at depths of $0-5,5-10,10-20,20-30,30-50,50-70$ and $70-100 \mathrm{~cm}$. Some profiles could only be dug to the bedrock and cannot reach a soil depth of $1 \mathrm{~m}$. In the laboratory, soil samples were air-dried and then sieved through a $2 \mathrm{~mm}$ mesh to remove gravels and roots. The obtained fine earth ( $<2 \mathrm{~mm}$ ) was used for the further analysis.

The fine earth were ground in a ball mill (Retsch MM20, Germany) and its total C (TC) content were determined using an elemental analyser (Euro Vector EA3000, Italy). The soil inorganic $C$ was analysed using a carbonate analyser (Eijkelkamp, Netherlands). The SOC content was calculated as the difference between the TC and SIC (Lange et al. 2015).

Climate data

Table 1 in our previous work has listed average MAP and MAT of each grassland type sites. In this study, we used the aridity index to indicate the degree of aridity. Aridity index was defined as the ratio of the MAP to potential evapotranspiration. It involves both MAP and potential evapotranspiration and therefore a more accurate metric of aridity. The potential evapotranspiration of each sampling site was derived using the Consortium for Spatial Information (http://www.cgiar-csi.org/).

\section{Statistical analysis}

To assess the effects of woody plants across the six grassland types, we used a two-way ANOVA and general linear-mixed models to assess the main and interactive effects of grassland types and physiognomic types (there also had explanatory variable "soil depth" on SOC content) on ANPP and SOC 
content. Then Tukey's multiple-range test was used to compare the differences in ANPP and SOC content between specific combinations of grassland and physiognomic types. We also used general linear-mixed models to further explore the effects of aridity index and physiognomic types (there also had explanatory variable "soil depth" on SOC content) on ANPP and SOC content. To elucidate the reasons for the effects on SOC storage, we used general linear-mixed models to explore the main and interactive effects of grassland types, ANPP, BGC and soil depth on SOC content and then used a simple linear regression to evaluate the relationship between the SOC content at different depths and ANPP and BGC in each grassland type. All the analysis was conducted using GenStat (19th, VSN International, UK).

\section{Results}

Grassland types, physiognomic types and their interaction had a significant effect on ANPP (Table 2). ANPP both in pure and wooded grasslands increased significantly from desert to mountainous meadow (Fig. 1a). They were negatively correlated with aridity index (Tables S1; Fig. S1a). In three arid grassland types, pure grasslands had a higher ANPP than wooded grasslands while in other three less arid types, wooded grasslands had a higher ANPP (Fig. 1a).

Table 2

The effects of grassland types (GT) and physiognomic types (PT) on aboveground primary productivity (ANPP)

\begin{tabular}{|llllll|}
\hline Dependent Variables & Explanatory terms & DF & SS (\%) & MS & $P$ value \\
\hline ANPP & GT & 5 & 66.81 & 28093.7 & $<0.001$ \\
\hline PT & 1 & 2.72 & 5712.2 & $<0.001$ \\
\hline GT*PT & 5 & 9.18 & 3861.8 & $<0.001$ \\
\hline Residual & 272 & 21.29 & 164.6 & \\
\hline ANPP of & GT & 5 & 63.15 & 28062.1 & $<0.001$ \\
herbaceous plants & & & & & \\
\hline & PT & 1 & 14.69 & 24270.0 & $<0.001$ \\
\hline & GT*PT & 5 & 3.16 & 1043.9 & $<0.001$ \\
\hline Residual & 272 & 18.99 & 115.3 & \\
\hline $\begin{array}{l}\text { ANPP of } \\
\text { woody plants }\end{array}$ & GT & 5 & 30.22 & 2309.2 & $<0.001$ \\
\hline & Residual & 100 & 69.78 & 266.6 & \\
\hline DF: degree of freedom; SS (\%): percentage sum of square; MS: mean square. The same below \\
\hline
\end{tabular}


The ANPP of herbaceous plants was significantly affected by grassland types, physiognomic types and their interaction (Table 2). See Fig. 6a in our previous work for the difference in ANPP of herbaceous plants (in our previous work, the ANPP of herbaceous plants was expresses as the living aboveground $\mathrm{C}$ of herbaceous plants) across grassland and physiognomic types.

The ANPP of woody plants was affected by grassland types and increased from desert to mountainous meadow (Table 2; Fig. 1b). It was negatively correlated with aridity index (Table S1; Fig. S1 b).

Grassland types, physiognomic types, soil depth and their interaction had a significant effect on SOC content (Table 3). SOC content at different depth both in pure and wooded grasslands increased significantly from desert to mountainous meadow (Fig. 2) and were negatively related to aridity index (Table S2; Fig.S2). The significant differences in SOC content between the two physiognomic types were mostly confined to the upper soil layer (Fig. 2). In arid types, pure grasslands had a higher SOC content at the depth of $0-5 \mathrm{~cm}, 5-10 \mathrm{~cm}$ and $10-20 \mathrm{~cm}$ (Fig. 2a, b, c) while in less arid types, wooded grasslands had a higher SOC content at the $0-5 \mathrm{~cm}, 5-10 \mathrm{~cm}, 10-20 \mathrm{~cm}$ and $20-30 \mathrm{~cm}$ (Fig. 2a, b, c, d).

Table 3

The effects of grassland types (GT), physiognomic types (PT) and soil depth (SD) on soil organic carbon (SOC) content

\begin{tabular}{|lllll|}
\hline Explanatory terms & DF & SS (\%) & MS & $P$ value \\
\hline GT & 5 & 75.82 & 92019.57 & $<0.001$ \\
\hline PT & 1 & 0.03 & 183.96 & $<0.001$ \\
\hline SD & 1 & 11.59 & 70339.85 & $<0.001$ \\
\hline GT*SD & 5 & 6.90 & 8379.72 & $<0.001$ \\
\hline PT*SD & 1 & 0.03 & 211.00 & $<0.001$ \\
\hline GT*PT & 5 & 1.29 & 1561.41 & $<0.001$ \\
\hline GT*PT*SD & 5 & 0.29 & 352.57 & $<0.001$ \\
\hline Residual & 1727 & 4.03 & 14.19 & \\
\hline
\end{tabular}

Grassland types, soil depth and their respective interaction with ANPP and BGC has a significant effect on SOC content (Table 4). Further analysis showed that in desert and desert steppe, SOC content at the upper soil layer was positively related to ANPP and in all three arid types, it was positively related to BGC (Table 5,6$)$. In less arid types, SOC content at the upper soil layer was only positively related to ANPP (Table 5). 
Table 4

The effects of grassland types (GT), soil depth, aboveground primary productivity (ANPP) and belowground biomass carbon

(BGC) on soil organic carbon (SOC) content

\begin{tabular}{|lllll|}
\hline Explanatory terms & DF & SS (\%) & MS & Pvalue \\
\hline GT & 5 & 75.82 & 92019.57 & $<0.001$ \\
\hline SD & 1 & 11.72 & 71142.26 & $<0.001$ \\
\hline ANPP & 1 & 0.44 & 2657.15 & $<0.001$ \\
\hline BGC & 1 & 0.09 & 523.29 & $<0.001$ \\
\hline GT*SD & 5 & 6.87 & 8342.51 & $<0.001$ \\
\hline ANPP*SD & 1 & 0.008 & 475.61 & $<0.001$ \\
\hline BGC*SD & 1 & 0.00 & 55.41 & 0.067 \\
\hline GT*ANPP & 5 & 0.12 & 150.50 & $<0.001$ \\
\hline GT*BGC & 5 & 0.12 & 149.80 & $<0.001$ \\
\hline GT* ANPP*SD & 5 & 0.04 & 40.62 & $<0.05$ \\
\hline GT*BGC*SD & 5 & 0.04 & 44.61 & $<0.05$ \\
\hline Residual & 1715 & 4.64 & 16.45 & \\
\hline
\end{tabular}

Table 5

Coefficients of determination $\left(\mathrm{R}^{2}\right)$ between aboveground primary productivity (ANPP) and soil organic carbon (SOC) content at different depth. Abbreviations are the same as those in Table 1. Asterisks indicate the significance level: ${ }^{*} P<0.05 ; * \star P<0.01 ; * \star \star P<0.001$

\begin{tabular}{|llllllll|}
\hline Grassland types & $\mathbf{0 - 5} \mathbf{c m}$ & $\mathbf{5 - 1 0} \mathbf{c m}$ & $\mathbf{1 0 - 2 0} \mathbf{c m}$ & $\mathbf{2 0 - 3 0} \mathbf{c m}$ & $\mathbf{3 0 - 5 0} \mathbf{c m}$ & $\mathbf{5 0 - 7 0} \mathbf{c m}$ & $\mathbf{7 0 - 1 0 0 c m}$ \\
\hline TD & $0.08^{\star}$ & $0.10^{\star \star}$ & $0.08^{\star}$ & $0.059^{\star}$ & 0.05 & 0.037 & 0.04 \\
\hline TSD & 0.12 & 0.10 & 0.06 & 0.029 & 0.001 & 0.058 & 0.002 \\
\hline TDS & 0.05 & $0.061^{\star}$ & $0.07^{\star}$ & $0.10^{\star \star}$ & $0.113^{\star \star}$ & 0.103 & 0.129 \\
\hline TS & $0.15^{\star \star \star}$ & $0.172^{\star \star \star}$ & $0.13^{\star \star}$ & $0.06^{\star}$ & 0.012 & 0.027 & 0.028 \\
\hline TMS & $0.43^{\star \star}$ & $0.28^{\star}$ & $0.27^{\star}$ & 0.12 & 0.138 & $0.292^{\star}$ & $0.266^{\star}$ \\
\hline MM & $0.24^{\star \star}$ & $0.20^{\star}$ & $0.15^{\star}$ & 0.07 & 0.004 & 0.002 & $0.231^{\star}$ \\
\hline
\end{tabular}


Table 6

Coefficients of determination $\left(R^{2}\right)$ between belowground biomass carbon (BGC) and soil organic carbon (SOC) content at different depth. Abbreviations are the same as those in Table 1. Asterisks indicate the significance level: $* P<0.05 ; * \star P<0.01 ; * \star \star P<0.001$

\begin{tabular}{|c|c|c|c|c|c|c|c|}
\hline Grassland types & $0-5 \mathrm{~cm}$ & $5-10 \mathrm{~cm}$ & $10-20 \mathrm{~cm}$ & $20-30 \mathrm{~cm}$ & $30-50 \mathrm{~cm}$ & $50-70 \mathrm{~cm}$ & $70-100 \mathrm{~cm}$ \\
\hline TD & $0.37 * \star \star$ & $0.32 * \star \star$ & $0.25^{\star \star \star}$ & $0.11^{\star \star}$ & $0.10^{*}$ & $0.12^{*}$ & $0.13^{*}$ \\
\hline TSD & 0.28 *夫 & $0.40 * \star \star$ & $0.36 * \star \star$ & $0.24^{\star \star}$ & 0.13 & 0.07 & 0.01 \\
\hline TDS & $0.16 * \star \star$ & $0.14^{\star \star}$ & $0.14^{\star \star}$ & $0.17 * \star \star$ & $0.12^{\star *}$ & 0.07 & 0.08 \\
\hline TS & 0.0001 & 0.0001 & 0.001 & 0.0001 & 0.003 & 0.001 & 0.002 \\
\hline TMS & 0.16 & 0.12 & 0.035 & 0.014 & 0.16 & $0.20 *$ & 0.22 \\
\hline MM & 0.001 & 0.0001 & 0.024 & 0.073 & 0.05 & 0.11 & 0.09 \\
\hline
\end{tabular}

\section{Discussion}

The difference between our this study and previous one was that we used a large number replicate but unpaired pure and wooded grassland sites to assess the effects of woody plants across Xinjiang at a regional scale. Moreover, we assessed the effects along the aridity gradient represented by the six grassland types to explore the mediation of climate conditions on the effects.

In our study, the effect of woody plants on ANPP was negative in arid grassland types but positive in less arid types, which matched with our previous finding that the wetter conditions promoted a more positive effect on AGC (Liu et al. 2020). Knapp et al. (2008) also found higher MAP promoted the increases in ANPP with woody plant encroachment in North American. A biotic mechanism for this finding they inferred was that woody plants had a canopy architecture that enabled them to display greater leaf area than the herbaceous plants in mesic regions. In this study, we separated the ANPP in wooded grasslands into that of herbaceous and woody plants to explore the mediation of climate. Our previous work found woody plants had a more negative impact on the ANPP of herbaceous plants (expressed as the living AGC of herbaceous plants in previous study) in three arid grassland types, however, it increased vegetation- level AGC because they had higher living AGC than herbaceous plants (Liu et al. 2020). However, in this study, the ANPP of woody plants cannot offset the reduced amount in those of herbaceous plants in these types, which did not support our prediction. This may be due to the fact that woody plants grow slowly and have a long life span and their biomass of current year (NPP) only account for a small proportion of their total biomass. The mediation of climate conditions on the effect on ANPP was similar to that on AGC in our previous study. Water availability limits the maximum woody cover and there had the relatively lower ANPP of woody plants in three arid types, which also can partly explain the negative effect on ANPP in these types (Chen et al. 2015; Sankaran et al. 2005). Our previous study found that woody plants had a weaker impact on the ANPP of herbaceous plants in other three less arid types probably because the improved water availability permitted more herbaceous plants coexist with woody plants (Liu et al. 2020; Tielbörger and Kadmon 2000). The improved water availability also 
led to an increase in the cover and density and thereby of ANPP of woody plants. These findings can explain the positive effect on ANPP in less arid types.

As we predicted, the effect on SOC storage was negative in arid grassland types while it was positive in less arid types. In arid grassland types, the positive relation between SOC content at the upper layer and ANPP and BGC indicated that the negative effect on ANPP and BGC led to that on SOC storage. In less arid types, the positive effect on SOC at the upper layer mainly attributed to that on ANPP. The neutral of woody plants on BGC that we have found in previous study also contributed to the positive effect on SOC content in these types (Liu et al. 2020). Our two studies showed that the effects of woody plants on ANPP, BGC and SOC storage along aridity gradients were almost coupled. This confirmed that climate conditions mediated the effects of woody plants on SOC storage through their influence on the amount of plant inputs.

In this study, a more negative impact of woody plants on the production of herbaceous plants led to a negative on ANPP in arid grassland types. Our previous work also found that woody plants had a more negative impact on the production of herbaceous plants and allocated less biomass to roots than herbaceous plants, and thereby they cannot make up for the greater loss in the BGC of herbaceous plants and had a negative effect on vegetation-level BGB in these types. Similarly, the decrease in SOC storage in the study of Jackson et al. (2002) was due to more loss of herbaceous plant production (Goodale and Davidson 2002). In arid types, the loss of grass cover and the increase in bare soil may also enhance wind erosion and thus the loss of nutrient-rich soil particles (Li et al. 2008). This finding agreed with that of Soliveres et al. (2014) who found that in global drylands, plant diversity and multifunctionality were associated with the relative woody cover and they decreased once a threshold in the relative woody cover has been reached. Our findings also further supported the points of Soliveres et al. (2014) that the mixed effects of woody plant encroachment was at least due to the difference in woody dominance and there was a need to consider differing levels of woody dominance to properly assess the effects of woody plant encroachment.

In our study, the wetter conditions promoted the positive effect of woody plant encroachment on SOC storage, which was consistent with the findings from the study of Li et al. (2016) who found that at a global scale, higher precipitation enhanced the increase in SOC content through increasing ANPP of woody plants after woody plant encroachment. In our study, the wetter conditions promoted the positive effect on SOC storage not only by increasing the ANPP of woody plants but also by weakening the negative impact of woody plant encroachment on the production of herbaceous plants and thus increasing ANPP and BGC. This finding expanded our understanding about the mediation of climate conditions on the effects of woody plant encroachment on SOC storage. However, previous studies observed an inverse relationship between the change in SOC storage and MAP. In addition to the scale of the analysis and climate zone, these inconsistent results were probably because grazing, soil texture and the species, cover and age of woody plants exert a local influence on the effects of woody plant encroachment on SOC storage (Barger et al. 2011). 
Our two studies have completely assessed the effect of woody plant encroachment on aboveground and underground $\mathrm{C}$ pools of arid grasslands using a consistent sampling and measuring methods. Grasslands stored most of $\mathrm{C}$ in soil and the effect of woody plant encroachment on SOC storage may dominate that on total ecosystem $\mathrm{C}$ storage. Our findings enabled us to highlight that there is a need to measure SOC storage in both pure and wooded grasslands to estimate accurately total ecosystem C storage of grasslands. Our previous study found a negative effect of woody plants on total plant $C$ storage in arid grasslands and forecasted woody plant encroachment would decrease plant $\mathrm{C}$ storage in grasslands due to the predicted increases in aridity in the future in Xinjiang. In this study, we further found the evidences that increasing aridity in the future would decrease ANPP and SOC with woody plant encroachment in grasslands.

\section{Conclusions}

Woody plants had effects on the ANPP and SOC storage compared with pure grassland in Xinjiang, and the direction and strength of the effects varied with grassland types which represent the variation of climate conditions. The climate conditions mediated the effects by affecting the production of woody and herbaceous plants as well as the impact of woody plants on the production of herbaceous plants.

\section{Declarations}

\section{Acknowledgements}

This work was financially supported by National Natural Science Foundation of China-Xinjiang joint fund (31500450, U1603235) and the strategic priority research program of the Chinese Academy of Sciences (XDA05050405). We are grateful to Hongqi Wu, Hongtao Jia, Ning Li, Yanmin Fan, Wentai Zhang, Bolang Chen and Haibin Gu from Xinjiang Agriculture University for their assistance in plant and soil sampling.

\section{References}

Asner GP, Archer S, Hughes RF, Ansley RJ, Wessman CA (2003) Net changes in regional woody vegetation cover and carbon storage in Texas drylands, 1937-1999. Glob Change Biol 9: 316-335

Barger NN, Archer SR, Campbell JL, Huang CY, Morton JA, Knapp AK (2011) Woody plant proliferation in North American drylands: a synthesis of impacts on ecosystem carbon balance. J Geophys Res 116: G00K07

Chen L, Li H, Zhang P, Zhao X, Zhou L, Liu T, Hu H, Bai Y, Shen H, Fang J (2015) Climate and native grassland vegetation as drivers of the community structures of shrub-encroached grasslands in Inner Mongolia, China. Landscape Ecol 30: 1627-1641

D'odorico P, Okin GS, Bestelmeyer BT (2012) A synthetic review of feedbacks and drivers of shrub encroachment in arid grasslands. Ecohydrology 5: 520-530

Page $12 / 19$ 
Eldridge DJ, Bowker MA, Maestre FT, Roger E, Reynolds JF, Whitford WG (2011) Impacts of shrub encroachment on ecosystem structure and functioning: towards a global synthesis. Ecol Lett 14: 709-722

Eldridge DJ, Soliveres S, Bowker MA, Val J (2013) Grazing dampens the positive effects of shrub encroachment on ecosystem functions in a semi-arid woodland. Journal of Appl Ecol 50: 1028-1038

Goodale CL, Davidson EA (2002) Carbon cycle: uncertain sinks in the shrubs. Nature 418: 593-594

Hibbard K, Schimel D, Archer S, Ojima D, Parton W (2003) Grassland to woodland transitions: integrating changes in landscape structure and biogeochemistry. Ecol Appl 13: 911-926

House JI, Archer S, Breshears DD, Scholes RJ, Participants NTGI (2003) Conundrums in mixed woodyherbaceous plant systems. J Biogeogr 30: 1763-1777

Hughes RF, Archer SR, Asner GP, Wessman CA, McMurtry C, Nelson J, Ansley RJ (2006) Changes in aboveground primary production and carbon and nitrogen pools accompanying woody plant encroachment in a temperate savanna. Glob Change Biol 12: 1733-1747

Jackson RB, Banner JL, Jobbágy EG, Pockman WT, Wall DH (2002) Ecosystem carbon loss with woody plant invasion of grasslands. Nature 418: 623

Jobbágy EG, Jackson RB (2000) The vertical distribution of soil organic carbon and its relation to climate and vegetation. Ecol Appl 10: 423-436

Knapp AK, Briggs JM, Collins SL, Archers AR, Bret-harte MS, Ewers BE, Peters DP, Young GS, Shaver GR, Pendall E, Cleary MB (2008) Shrub encroachment in North American grasslands: Shifts in growth form dominance rapidly alters control of ecosystem carbon inputs. Global Change Biol 14: 615-623

Lange M, Eisenhauer N, Sierra CA, Bessler H, Engels C, Griffiths RI, Mellado-Vázquez PG, Malik AA, Roy J, Scheu S (2015) Plant diversity increases soil microbial activity and soil carbon storage. Nat Commun 6 : 6707

Li H, Shen H, Chen L, Liu T, Hu H, Zhao X, Zhou L, Zhang P, Fang J (2016) Effects of shrub encroachment on soil organic carbon in global grasslands. Sci Rep 6: 28974

Li J, Okin GS, Alvarez L, Epstein H (2008) Effects of wind erosion on the spatial heterogeneity of soil nutrients in two desert grassland communities. Biogeochemistry 88: 73-88

Liao JD, Boutton TW, Jastrow JD (2006) Storage and dynamics of carbon and nitrogen in soil physical fractions following woody plant invasion of grassland. Soil Biol Biochem 38: 3184-3196

Liu YH, Cheng JH, Schmid B, Tang LS, Sheng JD (2020) Woody plant encroachment may decrease plant carbon storage in grasslands under future drier conditions. J Plant Ecol 13: 213-223 
Mcculley RL, Archer SR, Boutton TW, Hons FM, Zuberer DA (2004) Soil respiration and nutrient cycling in wooded communities developing in grassland. Ecology 85: 2804-2817

Montané F, Romanyà J, Rovira $\mathrm{P}$, Casals $\mathrm{P}$ (2010) Aboveground litter quality changes may drive soil organic carbon increase after shrub encroachment into mountain grasslands. Plant Soil 337:151-165

Pregitzer KS (2002) Fine roots of trees-a new perspective. New Phytol 154: 267-270

Sankaran M, Hanan NP, Scholes RJ, Ratnam J, Augustine DJ, Cade BS, Gignoux J, Higgins SI, Le Roux X, Ludwig F (2005) Determinants of woody cover in African savannas. Nature 438: 846

Scurlock J, Hall D (1998) The global carbon sink: a grassland perspective. Glob Change Biol 4: 229-233

Smith DL, Johnson LC (2004) Vegetation-mediated changes in microclimate reduce soil respiration as woodlands expand into grasslands. Ecology 85:3348-3361

Soliveres S, Maestre FT, Eldridge DJ, Delgado-Baquerizo M, Quero JL, Bowker MA, Gallardo A (2014) Plant diversity and ecosystem multifunctionality peak at intermediate levels of woody cover in global drylands. Global Ecol Biogeogr 23: 1408-1416

Tang X, Zhao X, Bai Y, Tang Z, Wang W, Zhao Y, Wan H, Xie Z, Shi X, Wu B, Wang G, Yan J, Ma K, Du S, Li S, Han S, Ma Y, Hu H, He N, Yang Y, Han W, Hei H, Yu G, Fang J, Zhou G (2018) Carbon pools in China's terrestrial ecosystems: new estimates based on an intensive field survey. Proc Natl Acad Sci USA: 10.1073/pnas. 1700291115

Tielbörger K, Kadmon R (2000) Temporal environmental variation tips the balance between facilitation and interference in desert plants. Ecology 81: 1544-1553

Van Auken OW (2000) Shrub invasions of North American semiarid grasslands. Ann Rev Ecol Syst 31: 197-215

Wessman CA, Archer S, Johnson LC, Asner GP (2012) Woodland expansion in US grasslands. In: Gutman G, Janetos AC, Justice CO, Moran EF, Mustard JF, Rindfuss RR, Skole D, Turnerll BL, Cochrane MA (ed) Land Change Science. Springer, Dordrecht, pp 185-208

Wheeler CW, Archer SR, Asner GP, McMurtry CR (2007) Climatic/edaphic controls on soil carbon/nitrogen response to shrub encroachment in desert grassland. Ecol Appl 17: 1911-1928

Xu P (1993) Grassland resources and their utilization in Xinjiang. Xinjiang Science and Technology Publishing Press, Urumqi

\section{Supplementary Table}


Table S1: The effect of physiognomic types (PT) and aridity index (Al) on aboveground primary productivity (ANPP)

\begin{tabular}{|c|c|c|c|c|c|}
\hline Dependent Variables & Explanatory terms & DF & SS (\%) & MS & $P$ value \\
\hline \multirow[t]{4}{*}{ ANPP } & PT & 1 & 1.59 & 3346.5 & $<0.05$ \\
\hline & $\mathrm{Al}$ & 1 & 48.01 & 100935.5 & $<0.001$ \\
\hline & $\mathrm{PT} * \mathrm{Al}$ & 1 & 4.89 & 10292.0 & $<0.001$ \\
\hline & Residual & 280 & 45.46 & 341.7 & \\
\hline \multirow{4}{*}{$\begin{array}{l}\text { ANPP of } \\
\text { herbaceous plants }\end{array}$} & PT & 1 & 18.12 & 29922.1 & $<0.001$ \\
\hline & $\mathrm{Al}$ & 1 & 39.37 & 65030.8 & $<0.001$ \\
\hline & $\mathrm{PT} * \mathrm{Al}$ & 1 & 0.35 & 582.8 & 0.127 \\
\hline & Residual & 280 & 42.16 & 248.7 & \\
\hline ANPP of & Al & 1 & 25.93 & 9907.0 & $<0.001$ \\
\hline \multicolumn{6}{|l|}{ woody plants } \\
\hline & Residual & 104 & 74.07 & 272.1 & \\
\hline
\end{tabular}

Table S2: The effect of physiognomic types (PT), aridity index (AI) and soil depth (SD) on soil organic carbon (SOC) content 


\begin{tabular}{lllll} 
Explanatory terms & DF & SS $(\%)$ & MS & $P$ value \\
\hline PT & 1 & 0.01 & 62.6 & 0.545 \\
\hline Al & 1 & 37.43 & 227109.2 & $<0.001$ \\
\hline SD & 1 & 9.76 & 59225.1 & $<0.001$ \\
\hline PT*Al & 1 & 1.17 & 7074.1 & $<0.001$ \\
\hline PT*SD & 1 & 0.01 & 67.5 & 0.529 \\
\hline Al*SD & 1 & 2.37 & 14407.2 & $<0.001$ \\
\hline PT*Al*SD & 1 & 0.34 & 2111.8 & $<0.001$ \\
\hline Residual & 1743 & 48.90 & 170.2 &
\end{tabular}

Figures 

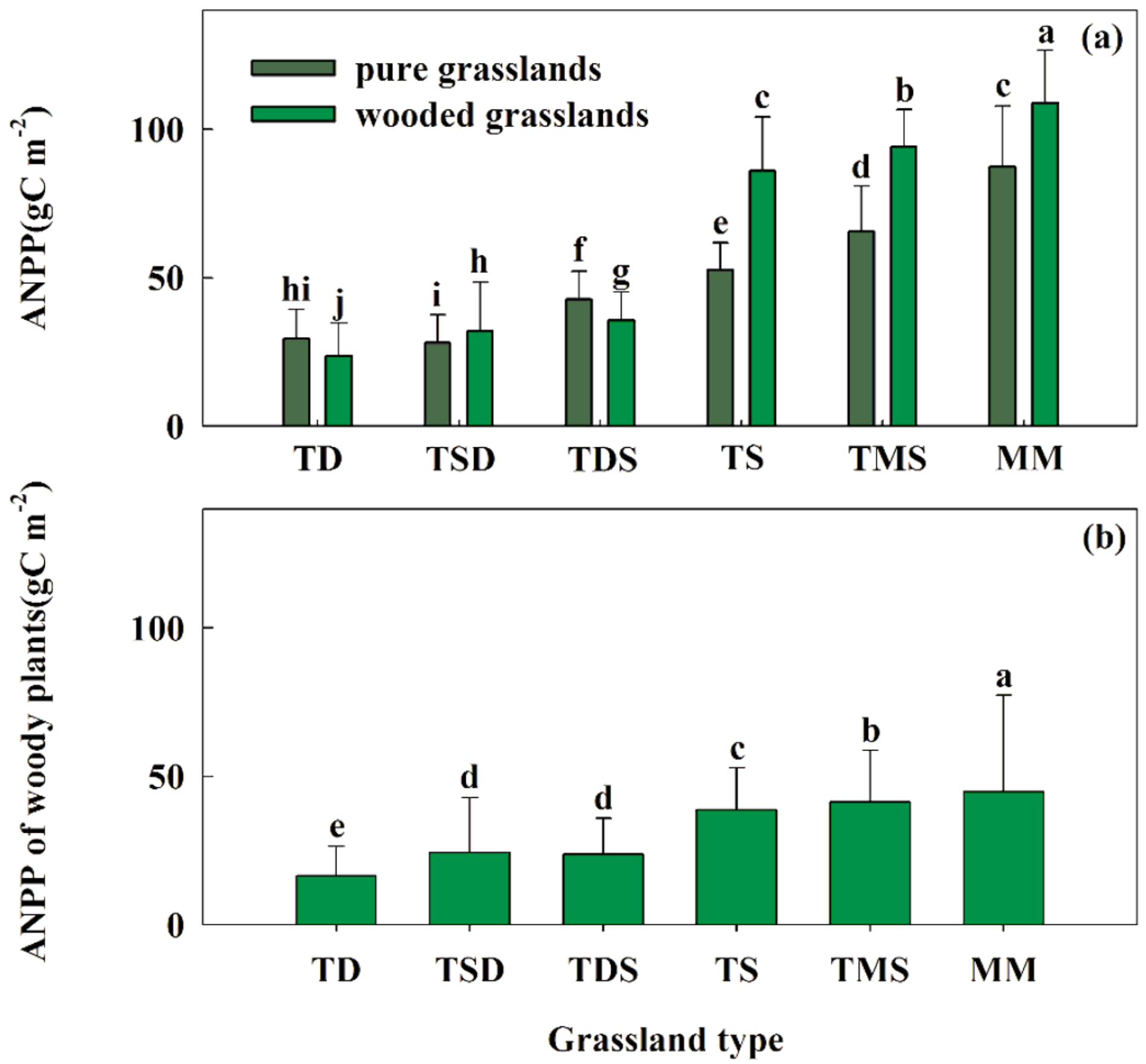

Figure 1

Aboveground primary productivity (ANPP) in pure and wooded grasslands and the ANPP of woody plants in wooded grasslands in the six grassland types. Abbreviations are the same as those in Table 1. Error bars represent one standard deviation. Different letters above the bars indicate significant differences between grassland and physiognomic types according to Tukey's multiple-range test $(P<0.05)$ 


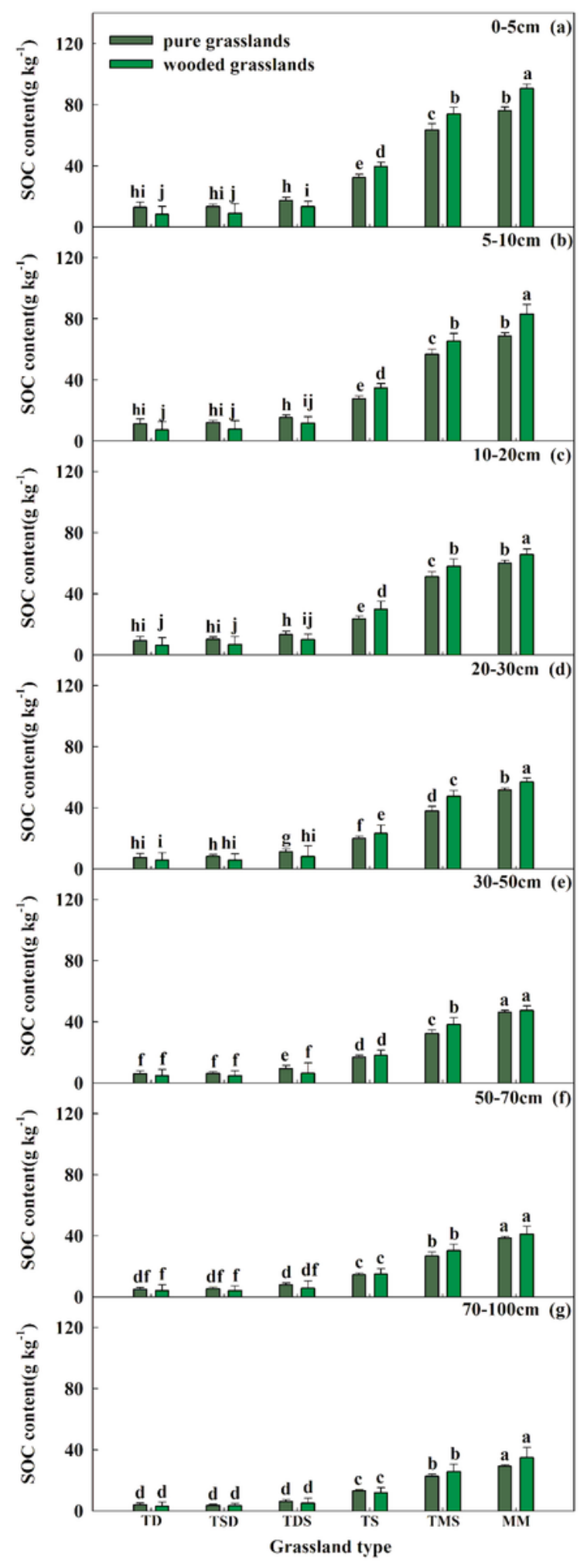

Figure 2

The vertical distribution of SOC content in pure and wooded grasslands in the six grassland types. Abbreviations are the same as those in Table 1. Error bars represent one standard deviation. Different letters above the bars indicate significant differences between grassland and physiognomic types according to Tukey's multiple-range test $(P<0.05)$ 


\section{Supplementary Files}

This is a list of supplementary files associated with this preprint. Click to download.

- Dataset.xIsx

- OnlineFig.S1.png

- OnlineFig.S2.png 